\title{
Learning styles of design students and the relationship of academic performance and gender in design education
}

\author{
O. Osman Demirbas*, Halime Demirkan ${ }^{1}$ \\ Department of Interior Architecture and Environmental Design, Faculty of Art, Design and Architecture, Bilkent University, \\ 06800 Bilkent, Ankara, Turkey
}

\begin{abstract}
The study focuses on design education using Experiential Learning Theory (ELT) and explores the effects of learning styles and gender on the performance scores of freshman design students in three successive academic years. Findings indicate that the distribution of design students through learning style type preference was more concentrated in assimilating and converging groups. Further study indicates that the first and third groups were found to be more balancing while the second group being mostly a southerner. The learning style preferences did not significantly differ by gender in all three groups. Although there is no consistency in all three groups, results indicate that the performance scores of males were higher in technology-based courses, whereas scores of females were higher in artistic and fundamental courses and in the semester academic performance scores (GPA). Also, it was found that the performance scores of converging and diverging students differed significantly in favor of converging students only in design courses. In design education, instructors should provide a strategy that is relevant to the style of each learner in design studio process.
\end{abstract}

(C) 2007 Elsevier Ltd. All rights reserved.

Keywords: Design education; Experiential learning; Learning styles

\section{Introduction}

In design studio, the knowledge acquired in various courses has to be integrated into the design process in order to find an optimal solution to the design problem. Schon $(1983,1987)$ observed that learning in the studio developed through a process he called 'reflection-in-action', however, research oriented to design education has not flourish (Waks, 1999, 2001). Recently, design educators have started to explore the characteristics of learning styles of students that can be used for the enhancement of learning in design (Demirbas, 2001; Demirbas \& Demirkan, 2003; Kvan \& Yunyan, 2005; Uluoğlu, 2000). This literature suggests that design students should learn by experiencing, reflecting, thinking and doing in the process of finding solutions to assigned design problems. Therefore, design education can be considered as being in line with the Experiential Learning Theory (ELT) of Kolb (1984). This study

\footnotetext{
* Corresponding author. Tel.: +90 312290 1515; fax: +90 3122664136.

E-mail addresses: demirbas@bilkent.edu.tr (O.O. Demirbas), demirkan@bilkent.edu.tr (H. Demirkan).

${ }^{1}$ Tel.: +90 312290 1465; fax: +90 3122664136 .
} 
aims to focus on learning in design education using Kolb's learning styles and explores the relationship between learning styles, gender and academic performance.

\section{Design education}

In design education, learning and teaching methods aim to balance the creative process with a critical awareness of more objective criteria in the development of a proposition. Each design outcome tends to be unique, non-repetitive and immanent in its conception and development. During a design project, the student transforms a field of inquiry into a proposition or scheme. The learning process is characterized by continual dialogue. Students learn from sharing information with one another and instructors, and from the critiques of the jury members. The most important learning experience comes from what is known in other disciplines as self-reflection, a skill central to the acquisition of all design knowledge and skills, and one that is consciously developed (Demirbas \& Demirkan, 2003; Newland, Powell, $\&$ Creed, 1987). Consequently, the learning process in design education can be underpinned by ELT of Kolb (1984).

The assessment process is distinctive to design education and is a considerable part of the learning process. At the end of the time allowed for the design project, each student's work is reviewed by a jury in front of an audience of fellow students, instructors and visiting critics from inside and/or outside the institution. At these sessions, the students present their design proposals, then the audience comment on and discuss the issues that it raises the quality of the design project. Critiques may be given to students in verbal, written and drawing forms. Other courses in the undergraduate curriculum are usually assessed through standard methods, such as coursework, examinations, papers and project-based work.

The graduates of a design department are expected to be highly motivated, technically competent and mentally prepared to deal with ideas at a professional level. The rationale of the curriculum has to enable the students to build up a model that will guide them to understand and apply the knowledge, skills, process and theories of design and to provide a balanced synthesis between the artistic, technological and humane aspects of the profession.

The curriculum of contemporary design education is studied under four categories. In the first category, there are fundamental courses that develop the design formation; the knowledge in these courses is generally theoretical rather than practice based. Secondly, there are technology-based courses that provide the scientific formation of design; the acquired knowledge in these courses is both theoretical and practice based. The third category consists of artistic courses that strengthen the base of design and expression; the acquired knowledge from these kinds of courses is the presentation techniques of preparing and expressing design ideas, so the expected outcomes are directly related to the application of them. Finally, there are design studio courses, which are a synthesis of the previous three categories (Demirbas, 2001; Uluoğlu, 1990). Design studio courses constitute the most important part of design education.

According to the characteristics of the different courses (fundamental, technology-based, artistic courses or design studios), different learning styles may be more effective in each. The recent studies showed that all learning styles are effective in different stages of the design studio process, since design studio is the combination of all other courses in architectural education (Bunch, 1993; Demirbas, 1997, 2001; Demirbas \& Demirkan, 2000, 2003; Teymur, 1992, 1996; Uluoğlu, 1990, 2000).

\section{Learning styles}

Slaats, Lodewijks, and Van der Sanden (1999: 489) state that understanding the "learning styles of students has a wide range of possible applications in education" from classifying the learning preferences of students to detecting potential learning problems at an early stage in order to choose the appropriate teaching methods. Many studies of learning styles have been conducted in the field of higher education (Biggs, 2001; Busato, Prins, Elshout, \& Hamaker, 2000; Coffield, Moseley, Hall, \& Ecclestone, 2004; Guild, 1994; Hartman, 1995; Vermetten, Lodewijks, \& Vermunt, 1999). Although the studies classify different learning types and/or styles in different ways, their aims and approaches are similar. Felder (1996) claims that since the instructional approaches around the cycle of learning models are similar, it is not important, which learning style instrument has been chosen. Among the various learning style theories, Kolb's (1984: 41) ELT that defines learning as "the process whereby knowledge is created through the transformation of experience. [and in which] Knowledge results from the combination of grasping and transforming experience" was chosen to underpin this study. Cassidy (2004: 423) describes learning styles in the ELT of Kolb "as the individual's intellectual approach to the processing of information". Consequently, each learner has her/his preferred way of 
percepting, organising and retaining that are distinctive and consistent (Chou \& Wang, 2000; Griggs, 1999; Hsu, 1999; Leutner \& Plass, 1998).

Kolb (1984) has built ELT on a set of theories as Dewey's pragmatism, Lewin's social psychology, Piaget's cognitive-development, Ruger's client-centered therapy, Maslow's humanism and Perls' Gestalt therapy. Kayes (2002) advocates that Kolb's learning theory provides one of the few comprehensive and fully generalized models among the other experiential models that employ dialectic inquiry. Kolb and Kolb (2005) explain the popularity of the ELT Bibliography with the 1876 entries by special emphasis on the two characteristics as having a holistic approach and being interdisciplinary.

Despite its popularity, there are criticisms to ELT either on the empirical limitations as validation and reliability of LSI or its theoretical background (Holman, Pavlica, \& Thorpe, 1997; Hopkins, 1993; Vince, 1998). Kayes (2002) reviews these critics and points to the problem of ELT as its failure to consider the relationship between social and personal learning. Furthermore, he suggests that elaborating the gap between personal and social knowledge with a special emphasis on language should broaden the theoretical base of ELT. Coffield et al. (2004) compare 13 models of learning styles based on the evidence provided by independent researchers (i.e. not the originators of the models) on four criteria as internal consistency, test-retest reliability, construct and predictive reliability. Kolb's (1999) LSI is found to be meeting only one criterion that is the test-retest reliability. Nevertheless, ELT is widely accepted as a comprehensive and generalized model and LSI provides a useful framework for learning in many disciplines and continues to have a considerable impact on design education.

ELT suggests that learning is a cycle that begins with experience, continues with reflection and later leads to action, that becomes a concrete experience for reflection (Kolb, 1984). In the Experiential Learning Model, there are four phases of the learning cycle, namely concrete experience (CE), reflective observation (RO), abstract conceptualization (AC) and active experimentation (AE) (see Fig. 1).

ELT portrays two bipolar learning dimensions, namely perceiving (the vertical axis in Fig. 1) and processing (the horizontal axis in Fig. 1). A combination of scores on the two dimensions classifies learners into one of four learning styles: accommodating (CE and $\mathrm{AE}$ ), diverging (CE and $\mathrm{RO}$ ), converging ( $\mathrm{AC}$ and $\mathrm{AE}$ ) and assimilating (AC and RO). From a hypothetical point of view, a learner would consciously move through all the phases of the learning cycle.

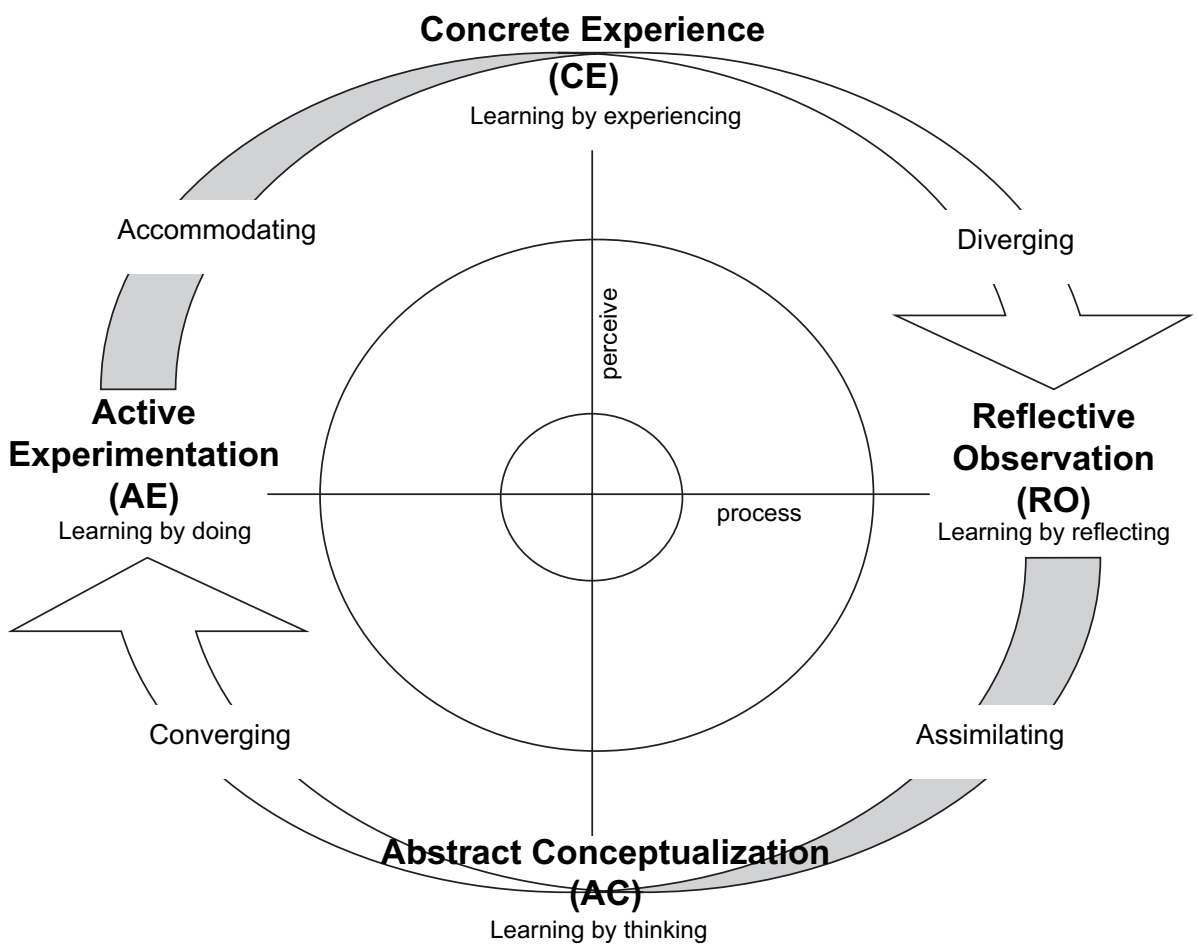

Fig. 1. Four learning phases of Experiential Learning Theory (revised from Kolb, 1999, p. 4). 
However, most of the studies showed that not all learners equally experience each phase of the cycle, nor is any phase of the cycle more important than the other phases. This suggests that the preference of learners among the phases of the cycle does not make them any better or worse learners (Kolb, 1984; Smith \& Kolb, 1996; Willcoxson \& Prosser, 1996).

Accommodating learners perceive through concrete experience (CE) and process by active experimentation (AE). Accommodating learners are most interested in doing things. They grasp their environment concretely through their feelings and utilize action to transform information (Hsu, 1999). They are risk takers and they enjoy finding out new experiences. They solve problems using a trial-and-error method instead of using their analytical abilities. Also, these learners rely on others for information and they prefer to work with others to do assignments, to set goals, to do field work and to test various approaches for design alternatives (Kolb \& Kolb, 2005).

Diverging learners perceive through concrete experience (CE) and process by reflective observation (RO). These learners are imaginative and emotional (Smith \& Kolb, 1996). They have the ability to synthesize and/or assimilate various observations for new idea generation (Hsu, 1999). They are less concerned with theorems and generalizations. Their approach to problem solving is not systematic, but is more creative in comparison to the other learning styles. These learners when working in-groups listen to the suggestions of others and accept critiques from them.

Assimilating learners perceive through active conceptualization (AC) and process by reflective observation (RO). They experience their world symbolically and transform information through thought (Demirbas \& Demirkan, 2003). They are more concerned with abstract concepts rather than practical applications. These learners prefer readings, lectures and exploring analytical models (Kolb \& Kolb, 2005).

Converging learners perceive through active conceptualization (AC) and process by active experimentation (AE). These learners bring logical, pragmatic and unemotional perspective to the problem solving process (Hsu, 1999). Their knowledge is organized and they do hypothetical-deductive reasoning while focusing on a specific problem (Smith \& Kolb, 1996). They are unemotional and prefer to focus on things rather than people (Smith \& Kolb, 1996). These learners prefer to experiment with new ideas, simulations and practical applications (Kolb \& Kolb, 2005).

Kolb's four original learning styles were expanded by Abbey, Hunt, and Weiser (1985) and then by Hunt (1987) to show nine distinct styles. As shown in Fig. 2, the Learning Style Inventory grid defined by Kolb (1976) at the 50th

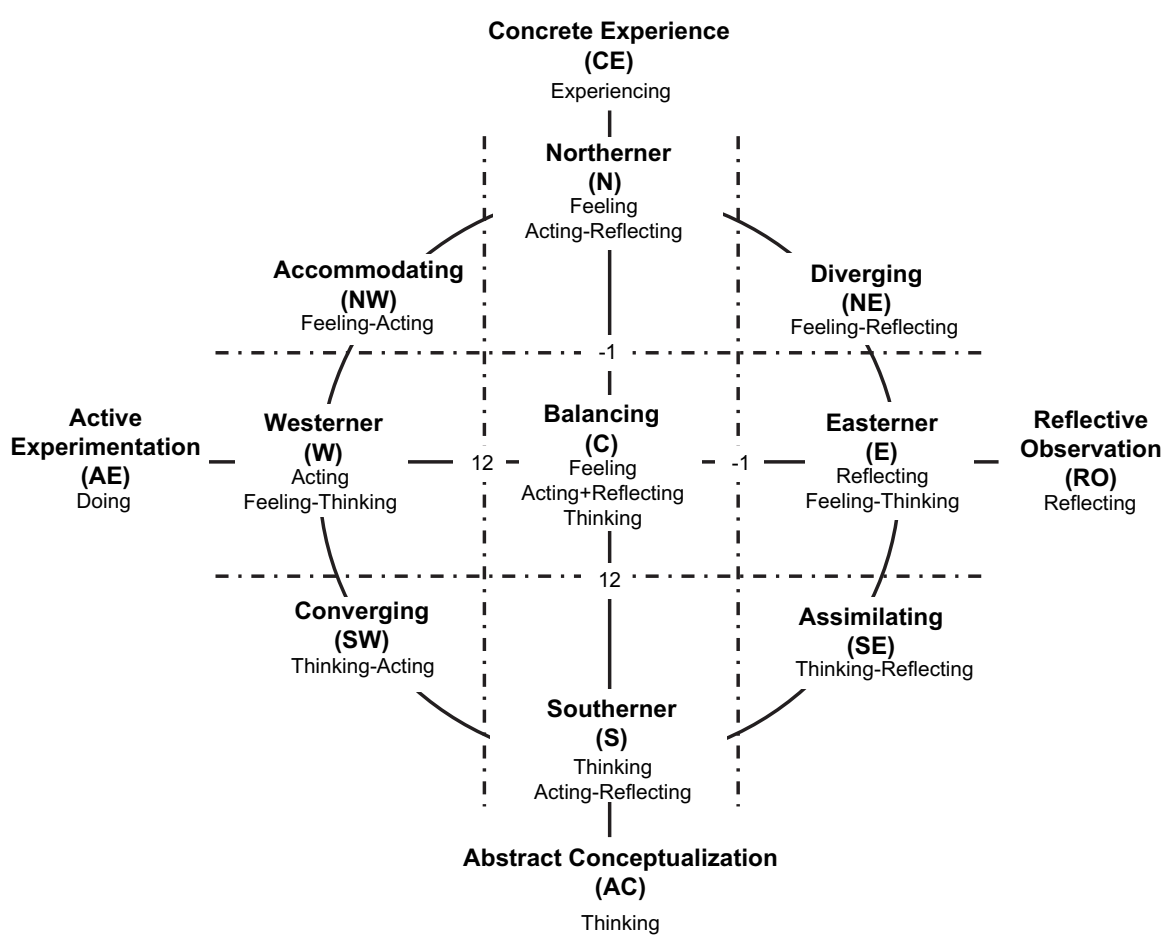

Fig. 2. The Nine-Region Learning Style type grid. 
percentiles of each axis is divided into three regions along each axis. The center region was named 'balancing' and represented learners who were in equilibrium in $\mathrm{AE}, \mathrm{CE}, \mathrm{RO}$ and $\mathrm{AC}$ (Mainemelis, Boyatzis, \& Kolb, 2002). In the Nine-Region Learning Style type grid, the 'active regions' are defined by percentiles greater than $66.67 \%$ (raw scores $\geq 12$ ), while the 'reflective regions' are defined by percentiles less than $33.33 \%$ (raw scores $\leq-1$ ) on the horizontal axis. On the vertical axis the 'concrete regions' are defined by percentiles less than $33.33 \%$ (raw scores $\leq-1$ ) and the 'abstract regions' by percentiles greater than $66.67 \%$ (raw scores $\geq 12$ ). Hunt (1987) identified four second order learning styles and named them Northerner, Easterner, Southerner and Westerner. The following descriptions of these styles also involve the weaknesses of learners in each style according to Hunt's (1987) explanation.

Northerner learners are specialized in perceiving through concrete experience (CE) while balanced in process (AE and RO). They combine the characteristics and abilities of diverging and accommodating learners. They are poor in conceptualizing or making meanings of experience (Hunt, 1987).

Easterner learners are specialized in processing by reflective observation (RO) while balanced in perceiving (CE and $\mathrm{AC}$ ). They combine both the learning skills of assimilating and diverging learners. They have trouble putting plans into action (Hunt, 1987).

Southerner learners are specialized in perceiving through abstract conceptualization (AC) while balanced in processing (AE and RO). They combine the learning skills of assimilating and converging learners. They do not provide feedback from emotions and their reflection is mechanical. These learners do not reflect their feelings in the design process.

Westerner learners are specialized in processing by active experimentation (AE) while balanced in perceiving (CE and $\mathrm{AC}$ ). They have learning skills of both accommodating and converging learners. These learners go directly from feelings to conceptualizing without considering concrete experience (Hunt, 1987).

\section{Relationship of learning style, gender and academic performance}

Besides the research on ELT that has focused on the concept of learning style and using LSI to assess individual learning style, there are studies that are concentrated on the relationship between gender and learning style. Belenky, Clinchy, Goldberger, and Tarule (1986) used gender in order to identify two epistemological orientations namely, connected knowing and separate knowing. They investigated a theoretical parallel between connected knowing and concrete experience (CE) as both emphasize feelings. Similarly, separate knowing was positively correlated with abstract conceptualization (AC) as both emphasize thinking. Knight, Elfenbein, and Martin (1997) using the Learning Style Inventory found no relationship between separate knowing and AC for males and females. For connected knowing a positive relationship was found for males, but not for females. Brew (2002) found that Learning Style Inventory is sensitive to gender and the validity of instrument score varies for females and males. The results of Brew's study were similar to Smith and Kolb's (1996) findings, but not acting as two bipolar dimensions for both genders. Brew (2002) argued that for males a preference for CE is not mutually exclusive from a preference for AC as it is for the female sample.

There are also a number of studies that have examined the relationship between learning style and academic performance in various disciplines. While some studies indicate relationships between performance scores and the converging learning style (Mainemelis et al., 2002; Rutz, 2003), others explain the learning style differences in student performance as the function of the chosen assessment technique. Holley and Jenkins (1993) examined the relationship between learning styles and four different accounting exam question formats (multiple-choice theory, multiple-choice quantitative, open-ended theory and open-ended quantitative). Their results indicated that there was a significant difference in learning style for all, but the multiple-choice quantitative format. They claimed that students with different learning style perform differently depending on the examination format. Therefore, different assessment strategies are required for measuring overall performance of students.

When all courses across the design curriculum are taken as a whole, it is possible to propose that all learning styles should be considered in design education. However, when the characteristics of different courses (fundamental, technology-based, artistic or design studio) are considered, different learning styles may be more effective. Since it is claimed that design studio is the combination of all other courses in design education (Bunch, 1993; Demirbas, 1997, 2001; Demirbas \& Demirkan, 2000; Teymur, 1992, 1996; Uluoğlu, 1990, 2000), all learning styles may be considered as effective in different stages of the design process. In general, it could be hypothesised that most design students belong to either accommodating and/or converging styles since the education is considered as practice based 
one. However, when the theory part of the design process is under consideration, the other learning styles could also be effective. The purpose of this study is to increase the instructor's awareness of learning styles to lead flexibility in teaching and enhance the communication between instructor and design students. Drawing on the fundamental theories of Dewey, Lewin, and Piaget (Kolb, 1984), ELT provides a framework for the enhancement of design education through curriculum development and design studio assessment. Previous studies on learning styles in the design field support this proposition (Demirbas \& Demirkan, 2003; Kvan \& Yunyan, 2005; Newland et al., 1987).

\section{Research questions}

Most of the recent studies on design education using ELT explored the effects of learning styles on the performance of design students with a cross sectional view. Also, these studies did not concentrate on the relationship between gender and learning style. Therefore, an experiment was designed to answer the following questions:

1. What is the learning style distribution of freshman design students across three years?

2. Are there any significant differences in the performance scores of design students in freshman courses across learning styles and gender?

\section{Method}

\subsection{Procedure}

Firstly, the purpose of the study was to find out the distribution of the four original learning styles of freshman design students. Also the nine distinct styles (Abbey et al., 1985) were used to analyze the distribution of freshman design students. Secondly, it sought to determine if there was any relationship between gender and learning styles and performance scores of freshman design students. Since various courses in design education involve different learning activities, the performance scores of design students who have different learning styles might differ in these courses. Gender was chosen as a second variable since it is an individual difference that can affect the performance scores of design students.

\subsection{Samples}

The three samples are comprised of freshman students of the Department of Interior Architecture and Environmental Design in three successive academic years at Bilkent University, Turkey. The reason for selecting the first year students was that design education had not yet affected their learning styles This assumption is based on the longitudinal research of Kolb and Kolb (2005) that shows increasing movement in learning style from a reflective to an active orientation through higher education years. In order to check the validity of the distribution of students on the Learning Style Type Grid, the study was repeated with three different groups who are the freshman students of the three successive academic years. The three samples were named as the first group, second group and third group. There were 111 freshman students in the first group, 88 freshman students in the second group and 74 freshman students in the third group. The age range was 17-27 in all groups. The mean age for the first group was 19.83 (std. dev. 0.13), for the second group was 20.14 (std. dev. 1.60) and for the third group was 19.76 (std. dev. 1.60). In the first group, there were $58(52.3 \%)$ males and $53(47.7 \%)$ females; in the second group, there were $51(58 \%)$ males and 37 (42\%) females; and in the third group, there were $24(32.4 \%)$ males and $50(67.6 \%)$ females. Participation was on a voluntary basis and the research was conducted through the regular freshman year courses. Participants were informed of their learning style preferences at the end of the study.

\subsection{Instruments}

The learning styles of the selected students were determined by using the third version of the Learning Styles Inventory Test (LSI) of Kolb (Kolb, 1999; Smith \& Kolb, 1996). At first, Concrete Experience (CE), Reflective Observation (RO), Abstract Conceptualisation (AC) and Active Experimentation (AE) scores for each participant were 
determined. After this process by subtracting each student's CE scores from AC scores and RO scores from AE scores, the learning style of each participant was classified either as 'accommodating', 'diverging', 'assimilating' or 'converging'. In addition, the distribution of the students according to the Nine-Region Learning Style Type Grid was determined (Hunt, 1987).

In the freshman year, there are four courses that are offered to the students in the department namely, Basic Design (the design studio course), Technical Drawing and Lettering (the technology-based course), Art and Culture (the fundamental course) and Drawing (the artistic course). A jury of experienced critics carries out assessment of design project in Basic Design course through a complex procedure of review and evaluation. Each jury member gives a letter grade that is based upon the rank position of the student with the group of fellow students. The Technical Drawing and Lettering and the Drawing courses grades are composed of the weighted-average of the studio-works, homework and exams. The Art and Culture course is assessed through examinations and papers.

The performance scores (grades) of the students in these four courses and the semester academic performance scores (GPA) were analyzed with respect to their learning styles and gender differences within each group. The official grading system of the university uses letter grades with pluses and minuses for performance scores. Passing grades range from ' $A$ ' to ' $D-$ ' with ' $F$ ' a failing grade. The highest grade is ' $A$ ' while the lowest is ' $F$ ' and each grade has a quality-point equivalence $(\mathrm{A}=4.0, \mathrm{~A}-=3.7, \mathrm{~B}+=3.3, \mathrm{~B}=3.0, \mathrm{~B}-=2.7, \mathrm{C}+=2.3, \mathrm{C}=2.0, \mathrm{C}-=$ $1.7, \mathrm{D}+=1.3, \mathrm{D}=1.0, \mathrm{D}-=0.7, \mathrm{~F}=0.0)$. A student's academic performance is determined at the end of each semester by computing the weighted-average of the grades achieved during that semester. These five different performance scores (the four course grades and GPA) were analyzed according to gender difference and learning styles.

\section{Results}

\subsection{Learning styles of students}

Using the results of the Learning Style Inventory, the distribution of the students according to the four learning styles was determined (Table 1). There was no significant difference between observed and expected frequency of the three different groups of freshman design students in their preferred learning style $\left(\chi^{2}=9.64\right.$, df $=6, p=$ 0.141). The distribution of each group according to the learning styles is depicted in Fig. 3 . Although there was no significant difference in all three groups, the number of accommodating learners was the lowest. In the first and second groups, the majority of learners were assimilating and converging while for the third group they were mostly converging.

Also, the distribution of the students according to the nine distinct styles was determined (Table 2). In the first and third groups, the general tendency of the distribution showed that the balancing learning style was the most preferred learning style (27.03\% in the first group and $27.02 \%$ in the third group). The students of these groups were balancing between thinking/feeling ( $\mathrm{AC}$ and $\mathrm{CE}$ ) and acting/reflecting ( $\mathrm{AE}$ and $\mathrm{RO}$ ). In the second group, the most preferred learning style was southerner (29.55\%). The southerner emphasizes thinking (AC) while balancing acting (AE) and reflecting (RO). As Hunt (1987) emphasized, these learners do not reflect their feelings in the design process. The classifications of the distribution according to nine distinct styles showed that in all three groups, the learning styles of the freshman design students were generally either close to the vertical axis (AC-CE) or the horizontal axis (AE-RO) of the Learning Style Type Grid. This result showed that most of the students with balancing learning style integrate $\mathrm{AC}$ and $\mathrm{CE}$ and $\mathrm{AE}$ and $\mathrm{RO}$. These findings supported the idea that design students are expected to learn

Table 1

The distribution of participants through the learning styles

\begin{tabular}{|c|c|c|c|c|c|c|}
\hline \multirow[t]{2}{*}{ Learning styles } & \multicolumn{2}{|l|}{ First group } & \multicolumn{2}{|c|}{ Second group } & \multicolumn{2}{|c|}{ Third group } \\
\hline & Frequency & Percentage & Frequency & Percentage & Frequency & Percentage \\
\hline Accommodating & 11 & 9.9 & 11 & 12.5 & 13 & 17.6 \\
\hline Diverging & 17 & 15.3 & 20 & 22.7 & 12 & 16.2 \\
\hline Assimilating & 38 & 34.2 & 28 & 31.8 & 14 & 18.9 \\
\hline Converging & 45 & 40.5 & 29 & 33.0 & 35 & 47.3 \\
\hline Total & 111 & 100.0 & 88 & 100.0 & 74 & 100.0 \\
\hline
\end{tabular}


(a)

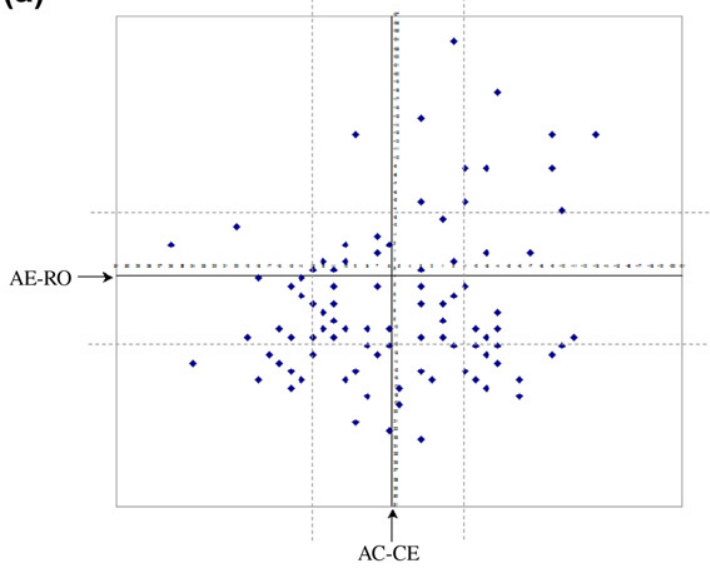

Learning style distribution of Group1

(b)

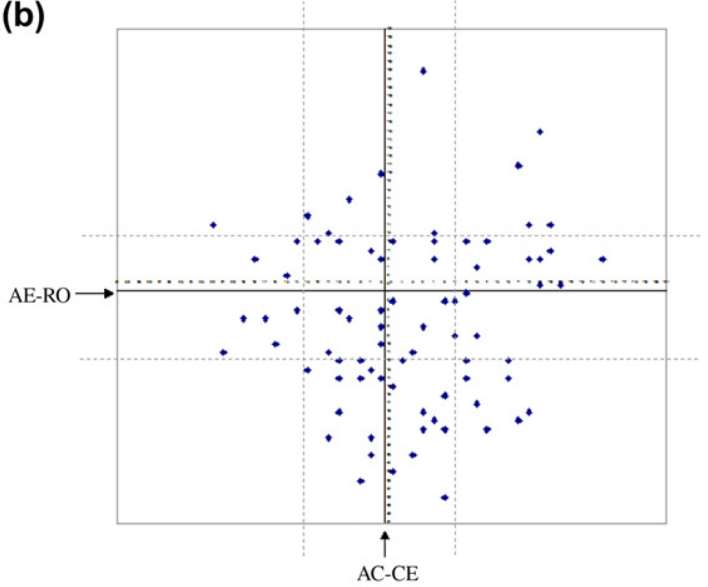

Learning style distribution of Group 2

(c)

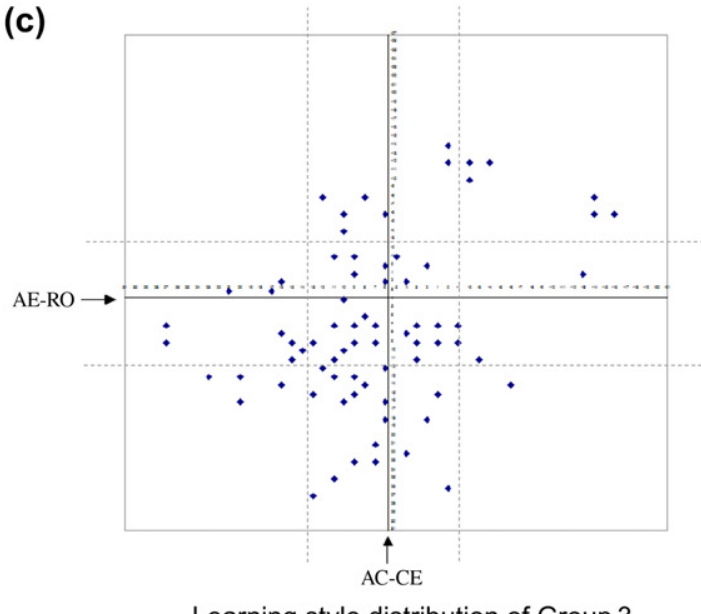

Learning style distribution of Group 3

Fig. 3. The learning style distribution of the three sample groups. (a) Learning style distribution of group 1, (b) learning style distribution of group 2 , and (c) learning style distribution of group 3 . 
Table 2

The percentage distribution of participants through the Nine-Region Learning Styles

\begin{tabular}{lccc}
\hline & First group & Second group & Third group \\
\hline First order & & & 4.55 \\
Accommodating & 0.90 & 7.95 & 1.35 \\
Diverging & 8.11 & 9.08 & 9.46 \\
Assimilating & 13.51 & 1.14 & 1.35 \\
Converging & 7.21 & & 9.46 \\
Second order & & 10.23 & 10.81 \\
North & 5.41 & 13.64 & 5.42 \\
East & 7.21 & 29.55 & 21.62 \\
South & 15.31 & 7.95 & 13.51 \\
West & 15.31 & & 27.02 \\
Central & & 15.91 & \\
Balancing & 27.03 & & \\
\hline
\end{tabular}

through a combination of experiencing, reflecting, thinking and doing in the process of finding solutions to assigned design problems.

\subsection{Learning style inventory scores of the students}

The learning style inventory scores of the three groups were calculated. The mean, standard deviation and range values of the six items $(\mathrm{CE}, \mathrm{RO}, \mathrm{AC}, \mathrm{AE}, \mathrm{AC}-\mathrm{CE}$ and $\mathrm{AE}-\mathrm{RO})$ are presented in Table 3 . These values are very close in all three groups.

The four basic (CE, RO, AC and $\mathrm{AE}$ ) and two combination items ( $\mathrm{AC}-\mathrm{CE}$ and $\mathrm{AE}-\mathrm{RO}$ ) showed a similar internal reliability as measured by Cronbach's alpha (Table 4). The alpha values ranged from 0.59 to 0.72 for group 1 ; from 0.57 to 0.73 for group 2, and from 0.51 to 0.73 for group 3. The values found in this study are lower than those of Kolb's study (Smith \& Kolb, 1996). Nevertheless, the found out alpha scores were considered as quite satisfactory in the existing study since the participants had a very constant profile as being freshman students, with a small age range, and sample sizes, as Schmitt (1996) argues that alpha values of 0.5 would not attenuate validity coefficient. The low reliability scores in $\mathrm{RO}, \mathrm{AE}$ and $\mathrm{AE}-\mathrm{RO}$ scales can be explained by the few number of learners with accommodating and diverging styles in all there groups.

\subsection{Pearson correlations of the learning styles dimensions}

Since the learning cycle is composed of two bipolar dimensions, the perceiving dimension measured by the combination item $\mathrm{AC}-\mathrm{CE}$ and the processing dimension measured by the $\mathrm{AE}-\mathrm{RO}$ combination item, they should be uncorrelated. As seen in Table 5, these items are uncorrelated in the first and second groups, but there is a significant but low correlation $(r=0.32)$ in the third group.

Table 3

The average raw scale scores and range values of the three groups

\begin{tabular}{|c|c|c|c|c|c|c|}
\hline & $\mathrm{CE}$ & RO & $\mathrm{AC}$ & $\mathrm{AE}$ & $\mathrm{AC}-\mathrm{CE}$ & $\mathrm{AE}-\mathrm{RO}$ \\
\hline \multicolumn{7}{|l|}{ First group } \\
\hline Mean (std. dev.) & $23.41(5.50)$ & $30.25(5.02)$ & $30.90(5.02)$ & $35.43(4.87)$ & $7.49(8.89)$ & $5.80(8.12)$ \\
\hline Range & $15-42$ & $15-41$ & $17-44$ & $21-46$ & -24 to 23 & -13 to 26 \\
\hline \multicolumn{7}{|l|}{ Second group } \\
\hline Mean (std. dev.) & $24.10(5.73)$ & $30.23(5.27)$ & $31.76(6.03)$ & $33.77(5.78)$ & $7.66(9.77)$ & $3.55(8.04)$ \\
\hline Range & $14-41$ & $17-41$ & $18-45$ & $22-47$ & -22 to 28 & -15 to 22 \\
\hline \multicolumn{7}{|l|}{ Third group } \\
\hline Mean (std. dev.) & $25.80(5.55)$ & $27.12(4.76)$ & $32.89(5.79)$ & $34.19(5.53)$ & $7.08(9.73)$ & $7.07(8.52)$ \\
\hline Range & $15-38$ & $16-37$ & $20-47$ & $19-45$ & -14 to 27 & -16 to 27 \\
\hline
\end{tabular}


Table 4

The reliability scores of the three groups

\begin{tabular}{llll}
\hline & \multicolumn{2}{l}{ Cronbach's standardized scale alpha } & \\
\cline { 2 - 4 } & First group & Second group & Third group \\
\hline Concrete experience (CE) & 0.72 & 0.70 & 0.67 \\
Reflective observation (RO) & 0.59 & 0.62 & 0.51 \\
Abstract conceptualism (AC) & 0.62 & 0.70 & 0.70 \\
Active experimentation (AE) & 0.61 & 0.63 & 0.67 \\
Abstract-concrete (AC-CE) & 0.71 & 0.73 & 0.73 \\
Active-reflective (AE-RO) & 0.59 & 0.57 & 0.60 \\
\hline
\end{tabular}

The prediction is that $\mathrm{CE}$ and $\mathrm{AC}$ items should not correlate with $\mathrm{AE}-\mathrm{RO}$ and $\mathrm{AE}$ and $\mathrm{RO}$ items should not correlate with AC-CE (Smith \& Kolb, 1996). As seen in Table 5, CE is correlated ( $r=-0.37$ ) with AE-RO item at a low level in the third group. Also, it is seen that AE is correlated $(r=0.21)$ with $\mathrm{AC}-\mathrm{CE}$ in the first group and $\mathrm{RO}$ is correlated $(r=-0.32)$ with $\mathrm{AC}-\mathrm{CE}$ in the third group both at a low level.

The dialectic poles (AC and CE, AE and RO) of both combination items should be negatively correlated in all three groups. Only in the second group, there was no significant negative correlation in AE and RO combination. Finally, the cross-dimensional items ( $\mathrm{CE} / \mathrm{RO}, \mathrm{AC} / \mathrm{AE}, \mathrm{CE} / \mathrm{AE}$, and $\mathrm{AC} / \mathrm{RO})$ were not correlated as highly as within dimension items in all three groups.

\subsection{Learning style characteristics according to gender}

In this study, the chi-square tests for all three groups showed that learning styles and gender were independent (Table 6). The frequencies of learning style preference were not significantly different by gender in all three groups (group 1, $\chi^{2}=5.094, \mathrm{df}=3, p=0.165$; group $2, \chi^{2}=1.752, \mathrm{df}=3, p=0.625$; group $3, \chi^{2}=1.635, \mathrm{df}=3, p=0.65$ ).

\subsection{Analysis of variance (ANOVA) of performance scores}

The performance scores of the students in four courses that are Basic Design (the design studio course), Technical Drawing and Lettering (the technology-based course), Art and Culture (the fundamental course) and Drawing (the artistic course) were considered separately as dependent variables. Since not all of the participants had taken all of the courses, the numbers of students were different in each course.

\subsubsection{Relationship of performance scores to gender}

In the first group, when the performance scores of students in the Technical Drawing and Lettering course were the dependent variable, there was a statistically significant mean difference across gender with a medium effect and an acceptable power level of $0.86\left(F=9.371, \mathrm{df}=1,103, p=0.003, \eta^{2}=0.083\right)$. The performance score means of males $(\mathrm{M}=1.17$, std. dev. $=0.95)$ and females $(\mathrm{M}=0.73$, std. dev. $=0.73)$ showed that males' performance scores were higher than females in the Technical Drawing and Lettering course (Table 7).

Table 5

Pearson correlations between learning phases and combined scores

\begin{tabular}{llllllllllll}
\hline & $\mathrm{AC}-\mathrm{CE} / \mathrm{AE}-\mathrm{RO}$ & $\mathrm{AC}-\mathrm{CE} / \mathrm{RO}$ & $\mathrm{AC}-\mathrm{CE} / \mathrm{AE}$ & $\mathrm{AE}-\mathrm{RO} / \mathrm{CE}$ & $\mathrm{AE}-\mathrm{RO} / \mathrm{AC}$ & $\mathrm{CE} / \mathrm{AC}$ & $\mathrm{RO} / \mathrm{AE}$ & $\mathrm{CE} / \mathrm{RO}$ & $\mathrm{AC} / \mathrm{AE}$ & $\mathrm{CE} / \mathrm{AE}$ & $\mathrm{AC} / \mathrm{RO}$ \\
\hline $\begin{array}{l}\text { First } \\
\text { group }\end{array}$ & 0.18 & -0.09 & $0.21^{*}$ & -0.13 & 0.18 & $-0.43^{* *}$ & $-0.35^{* *}$ & $-0.23^{*}$ & -0.13 & $-0.45^{* *}$ & $-0.41^{* *}$ \\
$\begin{array}{c}\text { Second } \\
\text { group }\end{array}$ & 0.10 & -0.10 & 0.06 & -0.08 & 0.09 & $-0.38^{* *}$ & -0.16 & $-0.29^{* *}$ & $-0.29 * *$ & $-0.40^{* *}$ & $-0.43^{* *}$ \\
$\begin{array}{c}\text { Third } \\
\text { group }\end{array}$ & $0.32 * *$ & $-0.32 * *$ & 0.22 & $-0.37 * *$ & 0.19 & $-0.47^{* *}$ & $-0.37 * *$ & 0.03 & -0.14 & $-0.54 * *$ & $-0.50^{* *}$ \\
\hline
\end{tabular}

*Correlation is significant at the 0.05 level (two-tailed).

** Correlation is significant at the 0.01 level (two-tailed). 
Table 6

The distribution of gender through learning styles

\begin{tabular}{|c|c|c|c|c|c|c|c|c|c|}
\hline & \multicolumn{3}{|c|}{ Group 1} & \multicolumn{3}{|c|}{ Group 2} & \multicolumn{3}{|c|}{ Group 3} \\
\hline & Male & Female & Total & Male & Female & Total & Male & Female & Total \\
\hline Accommodating & 7 & 4 & 11 & 8 & 3 & 11 & 5 & 8 & 13 \\
\hline Diverging & 9 & 8 & 17 & 12 & 8 & 20 & 4 & 8 & 12 \\
\hline Converging & 24 & 14 & 38 & 14 & 14 & 28 & 9 & 26 & 35 \\
\hline Assimilating & 18 & 27 & 45 & 17 & 12 & 29 & 6 & 8 & 14 \\
\hline Total & 58 & 53 & 111 & 51 & 37 & 88 & 24 & 50 & 74 \\
\hline
\end{tabular}

In the first group, when the performance scores of students in the Art and Culture course were the dependent variable, there was a statistically significant mean difference in gender with a medium effect but with a low power level of $0.66\left(F=5.736, \mathrm{df}=1,82, p=0.019, \eta^{2}=0.065\right)$. The performance score means of males $(\mathrm{M}=1.46$, std. dev. $=$ $1.09)$ and females $(M=2.12$, std. dev. $=1.14)$ showed that females' performance scores were higher than males in the Art and Culture course.

In the second group, no statistically significant difference was found between gender and the performance scores of students in any of the courses or GPA scores.

In the third group, there was a statistically significant mean difference of gender in the performance scores of students in the Art and Culture course, with a large effect and an acceptable power level of $0.90(F=11.021$, df $=1,49, p=$ $\left.0.002, \eta^{2}=0.184\right)$. The performance score means of males $(\mathrm{M}=1.06$, std. dev. $=1.24)$ and females $(\mathrm{M}=2.53$, std. dev. $=1.21$ ) showed that females' performance scores were higher than males in the Art and Culture course (Table 7).

In the third group, there was also a statistically significant mean difference of gender in the performance scores of students in the Drawing course with a large effect but with a low power level of $0.66(F=5.802, \mathrm{df}=1,50, p=0.02$, $\left.\eta^{2}=0.104\right)$. The performance score means of males $(\mathrm{M}=2.34$, std. dev. $=1.20)$ and females $(\mathrm{M}=3.10$, std. dev. $=$ 0.78) showed that females' performance scores were higher than males in the Drawing Course.

In the third group, the mean differences of gender in GPA scores were also statistically significant with a large effect and an acceptable power level of $0.86\left(F=9.388, \mathrm{df}=1,66, p=0.003, \eta^{2}=0.125\right)$. The academic performance score means of males $(\mathrm{M}=1.82$, std. dev. $=0.70)$ and females $(\mathrm{M}=2.44$, std. dev. $=0.74)$ showed that females' scores were higher than males' score.

\subsubsection{Relationship of performance scores to learning style}

In the second group, when the performance scores of students in the Basic Design Course were the dependent variable, there were statistically significant mean differences across learning style types with a large effect and a low power level of $0.67\left(F=2.947, \mathrm{df}=3,57, p=0.040, \eta^{2}=0.134\right)$. The Bonferroni test showed the performance scores of converging and diverging students differed significantly $(p=0.03)$ in a $95 \%$ confidence interval of $0.05-1.39$ in favor of converging students $\left(M_{\text {converging }}=2.36, M_{\text {diverging }}=1.64\right)$.

In the third group, when the performance scores of students in the Basic Design course were the dependent variable, there were statistically significant mean differences across learning style types with a large effect and a high power level of $0.93\left(F=5.577, \mathrm{df}=3,62, p=0.002, \eta^{2}=0.213\right)$. The Bonferroni test showed the performance scores of converging and diverging students differed significantly $(p=0.001)$ in a 95\% confidence interval of $0.34-1.80$ in favor of converging students $\left(M_{\text {converging }}=2.28, M_{\text {diverging }}=1.26\right)$; and the performance of accommodating and diverging students differ significantly $(p=0.004)$ in a 95\% confidence interval of $0.29-2.06$ in favor of accommodating students $\left(M_{\text {accommodating }}=2.51, M_{\text {diverging }}=1.26\right)$.

Table 7

Relationship of performance scores to gender

\begin{tabular}{lllll}
\hline & \multicolumn{2}{l}{ Performance scores in } & & Academic performance (GPA) \\
\cline { 2 - 4 } & Technology-based course & Fundamental course & Artistic course & \\
\hline Group 1 & $\mathrm{M}>\mathrm{F}$ & $\mathrm{F}>\mathrm{M}$ & No difference & No difference \\
Group 3 & No difference & $\mathrm{F}>\mathrm{M}$ & $\mathrm{F}>\mathrm{M}$ & $\mathrm{F}>\mathrm{M}$ \\
\hline
\end{tabular}

F: female; M: male. 


\section{Discussion and conclusion}

\subsection{On distribution of learning styles}

The Kolb's Learning Style Inventory test, one of the popular instruments for describing learning styles was used to determine which learning styles were predominant among freshman design students. By repeating the study on three different groups who are the design students from three successive academic years, it was found out that there was a specific distribution of learning styles for design students. Design students were found to be more concentrated in assimilating and converging groups.

This finding is contrary to Kolb's (1984) study in which he stated that the dominant style in architects is accommodating learners. A pioneer study in architecture considering learning styles was belonging to Newland et al. (1987). They had found that the architecture students favored reflective observation and abstract conceptualization where Kolb would call these students as assimilating learners. Both in Demirbas and Demirkan (2003) and Kvan and Yunyan's (2005) studies related to design students, accommodating learners were in minority of the four learning styles that confirms with this study. In Demirbas and Demirkan's (2003) study, most of the freshman students learning style were converging (33\%) and assimilating (31.8\%). In Kvan and Yunyan's (2005) study the majority of the students were diverging learners $(48.6 \%)$ in one group and assimilating learners $(40.9 \%)$ in the other group and both groups were junior students. The difference in distribution can be explained as Kolb (1984) stated that learning styles are shaped gradually by individual experience, since one group consists of freshmen and the other junior students. But Kvan and Yunyan (2005) explained the difference between these two studies in terms of cultural diversity.

In this study, it was found that the majority of learners were assimilating and converging in the first and second groups and converging in the third group (see Table 1). According to the scores, neither AC nor CE had a correlation with $\mathrm{AE}-\mathrm{RO}$, in the first and second groups (see Table 5). However, in the third group CE had a significant negative correlation ( $r=-0.37$ at 0.01 level, two-tailed) with AE-RO different from the other two groups and Kolb's study. This correlation showed that when the concrete experience (CE) score was high, learning activity on the horizontal axis of learning cycle shifted towards learning by reflecting (RO) and when concrete experience score was low, the learning activity shifted towards learning by doing (AE). In the third group, the negative correlation between CE and AE-RO was an expected result, since the number of converging learners was significantly high in this group (see Table 1).

When considering the nine distinct styles (Abbey et al., 1985; Hunt, 1987), design students in the first and third groups were concentrated in the balancing learning style that integrates thinking/feeling and acting/reflecting (see Table 2). Kolb and Kolb (2005) have found that learners with balanced learning profiles are more adaptive and flexible learners. Design students in the second group were concentrated in the thinking oriented southern region, which was different than the art students in Kolb and Kolb (2005: 201) study who have found that "more art students are in the eastern regions than in the western region". None of the three groups were concentrated either in the eastern or western regions, but they were balancing between acting and reflecting. This supports the proposition that design education is not only an art-oriented education, but is an integration of art and technology education.

The ELT (Kolb and Kolb, 2005: 194) proposes that 'learning is a holistic process of adaptation to the world. Not just the result of cognition, learning involves the integrated functioning of the total person - thinking, feeling, perceiving and behaving". The findings of this study show that design students use all these learning phases in design education. The findings in this study also support the previous work of the authors (Demirbas \& Demirkan, 2003) who found in their analysis of the design process that the learning cycle was a recursive one that uses experiencing, reflecting, thinking and acting. Since design is regarded as the combination of crafts, technologies and other disciplines, its education contains all the phases of the Experiential Learning cycle. In order to attain continuous improvements in the quality of learning in design education, departments should conduct systematic reviews of the curriculum to ensure that courses would cater for students with different learning styles.

\subsection{On gender and learning style characteristics}

Previous research related to Learning Style Inventory tests (Smith \& Kolb, 1996) shows that males were more abstract $(\mathrm{AC})$ than females on the perceiving dimension $(\mathrm{AC}-\mathrm{CE})$ and that there were no significant gender differences on the processing dimension (AE-RO). In Knight et al.'s (1997) research that was consisting of three separate studies, the males were mostly describing their learning style as emphasizing feelings (CE) rather than thinking (AC) in 
study 1. These two studies are pointing at the two different poles of the perceiving (AC-CE) dimension. However, no relationship was found between gender and learning style in studies 2 and 3 in Knight et al.'s (1997) work. In our study, it is found that learning styles and gender were independent for design students both on the perceiving and processing dimensions. This study provides further empirical support for the findings in studies 2 and 3 of Knight et al. (1997).

\subsection{On performance scores and gender}

Although there is no consistency all through the years, results indicate that there is a significant mean difference in performance scores across gender in technology-based, artistic and fundamental courses. The performance scores of males were higher in technology-based courses in the first group. Scores of females were higher in the fundamental course in the first and third groups. Besides, females had higher scores than males in artistic course and in academic performance (GPA) in the third group (see Table 7). Only in the second group, no statistical significant difference was found between gender and performance scores of students in any of the courses or GPA. This can be explained by being mostly southerner learners who do not provide feedback from emotions and they are concentrated in thinking. There is no study in design literature field to compare the findings of this study.

\subsection{On performance scores and learning style}

In the second and third groups, the performance scores of converging and diverging students in the Basic Design course were found to differ significantly in favor of converging students. Students who are converger learners are best at finding practical uses for ideas and theories (Hsu, 1999). Smith and Kolb (1996) state that they have the ability to solve problems and good in making decisions in finding solutions to problems. Since design is considered as a problem solving activity, the converger learners are successful in design process. Diverger learners are interested in gathering information (Hsu, 1999), although these learners are more creative compared to the others; they are not systematic in problem solving. This may explain the success of converging students in design courses. This result also supports the findings of two studies that were conducted among engineering (Rutz, 2003) and management students (Mainemelis et al., 2002).

\subsection{Implications to design education}

The design studio projects should provide the opportunity to employ different learning styles in design process. In the study conducted by Demirbas and Demirkan (2003: 437), "it was found that there were statistically significant differences between the performance scores of students having diverse learning styles at various stages of design process". The important point is to provide various learning experiences that emphasize different learning styles during design process. Each design instructor has his/her strategy while communicating with the student. As Schon (1984, 1987) proposed, the instructor should refer to all communication means as reflection-in-action. The goal of this research is to ensure that design instructors can relate concepts of learning to the specific conditions during the design process.

Furthermore, it is important to stimulate the diverging students for bringing to the studio their range of ideas and ways of problem solving. These students although are not successful in performance as converging students, they play an important role in the conceptual design phase in design studio. These students are the most creative ones (Hsu, 1999) and the other students can learn from them. Students also can be grouped into design teams that made up members with different learning styles. These teams may work on a larger scale design project compared to individual student project. Besides knowing the distinct learning styles may be helpful to the instructor in giving critiques to students to overcome their weaknesses towards learning process.

Various instruments as juries, drawing, three-dimensional models or written reports can be used for the assessment in design courses. In design education, the other courses are usually assessed through standard methods such as coursework, examination, paper and project-based work. The teachers should be encouraged to review their course and syllabi so all students have an opportunity to perform their best and be exposed to all learning styles (Messick, 1996). Increasing design instructors awareness of learning styles might lead to increase flexibility of teaching styles and enhance the communication between instructors and design students. 


\subsection{Limitations and future research}

The work presented here is subject to a number of limitations. First, the study is based on one design program at one university and it should be generalized by having data from several institutions. Data should be collected from multiple institutions with larger sample size. Second, it is based on freshmen design students and it should cover all four years of design education in order to have a general view of design education. Third, there may be cultural differences that are affecting the learning styles of students; therefore it has to be repeated in different countries.

Further work may examine the change in the learning styles of design students in the following years and professional life. Furthermore, a comparison between different countries may be of interest to scholars who are working in this field. Also the learning styles of individuals from different design disciplines as graphic design, landscape design, fashion design can be explored.

\section{Acknowledgements}

The authors would like to thank Prof. Dr. Giray Berberoğlu for his valuable guidance to the idea of this research on learning styles and for his insightful comments on the design of the experiment and the earlier version of this paper.

\section{References}

Abbey, D. S., Hunt, D. E., \& Weiser, J. C. (1985). Variations on a theme by Kolb: a new perspective for understanding counselling and supervision. The Counselling Psychologist, 13, 477-501.

Belenky, M., Clinchy, B., Goldberger, N., \& Tarule, J. (1986). Women's ways of knowing: The development of self, voice and mind. New York: Basic Books.

Biggs, J. (2001). The reflective institution: assuring and enhancing the quality of teaching and learning. Higher Education, 41, $221-238$.

Brew, C. R. (2002). Kolb's learning style instrument: sensitive to gender. Educational and Psychological Measurement, 62, $373-390$.

Bunch, M. A. (1993). Core curriculum in architectural education. San Francisco: Mellen Research University Press.

Busato, V. V., Prins, F. J., Elshout, J. J., \& Hamaker, C. (2000). Intellectual ability, learning style, personality, achievement motivation and academic success of psychology students in higher education. Personality and Individual Differences, 29, 1057-1068.

Cassidy, S. (2004). Learning styles: an overview of theories, models and measures. Educational Psychology, 24, 420-444.

Chou, H., \& Wang, T. (2000). The influence learning style and training method on self-efficacy and learning performance in WWW Homepage Design Training. International Journal of Information Management, 20, 455-472.

Coffield, F., Moseley, D., Hall, E., \& Ecclestone, K. (2004). Learning styles and pedagogy in post-16 learning: A systematic and critical review. London, UK: Learning and Skills Research Center.

Demirbas, O. O. (1997). Design studio as a life space in architectural education: Privacy requirements. Unpublished Masters Thesis. Ankara: Bilkent University.

Demirbas, O. O. (2001). The relation of learning styles and performance scores of the students in interior architecture education. Unpublished Ph.D. Dissertation. Ankara: Bilkent University.

Demirbas, O. O., \& Demirkan, H. (2000). Privacy dimensions: a case study in the interior architecture design studio. Journal of Environmental Psychology, 20, 53-63.

Demirbas, O. O., \& Demirkan, H. (2003). Focus on architectural design process through learning styles. Design Studies, $24,437-456$.

Felder, R. M. (1996). Matters of style. ASEE Prism, 6, 18-23.

Griggs, S. A. (1999). Learning styles counselling. Learning Styles. Available from http://www.ascd.org/services/eric/ericlngs.html (accessed 8.04.99).

Guild, P. (1994). Making sense of learning styles. School Administrator, 51, 8-13.

Hartman, V. F. (1995). Teaching and learning style preferences: transitions through technology. VCCA Journal, 9, 18-20.

Holley, J. H., \& Jenkins, E. K. (1993). The relationship between student learning style and performance on various test question formats. Journal of Education for Business, 68, 301-308.

Holman, D., Pavlica, K., \& Thorpe, R. (1997). Rethinking Kolb's theory of experiential learning in management education: the contribution of social constructionism and activity theory. Management Learning, 28, 135-148.

Hopkins, R. (1993). David Kolb's experiential learning-machine. Journal of Phenomenological Psychology, $24,46-62$.

Hsu, C. H. C. (1999). Learning styles of hospitality students: nature or nurture? Hospitality Management, 18, 17-30.

Hunt, D. E. (1987). Beginning with ourselves in practice, theory and human affairs. Cambridge MA: Brookline Books.

Kayes, D. C. (2002). Experiential learning and its critics: preserving the role of experience in management education. Academy of Management Learning and Education, 1, 137-149.

Knight, K. H., Elfenbein, M. H., \& Martin, M. B. (1997). Relationship of connected and separate knowing to the learning styles of Kolb, formal reasoning and intelligence. Sex Roles, 37, 401-414.

Kolb, D. A. (1976). Learning styles inventory. Boston: McBer \& Co.

Kolb, D. A. (1984). Experiential learning: Experience as the source of learning and development. Englewood Cliffs, NJ: Prentice Hall. 
Kolb, D. A. (1999). Learning style inventory. Version 3. Boston: Hay/McBer.

Kolb, A. Y., \& Kolb, D. A. (2005). Learning styles and learning spaces: enhancing experiential learning in higher education. Academy of Management Learning and Education, 4, 193-212.

Kvan, T., \& Yunyan, J. (2005). Students' learning styles and their correlation with performance in architectural design studio. Design Studies, 26, 19-34.

Leutner, D., \& Plass, J. L. (1998). Measuring learning styles with questionnaires versus direct observation of preferential choice behaviour in authentic learning situations: the visualizer/verbalizer behavior observation Scale (VV-Bos). Computers in Human Behaviour, $14,543-557$.

Mainemelis, C., Boyatzis, R., \& Kolb, D. A. (2002). Learning styles and adaptive flexibility: testing experiential learning theory. Management Learning, 33, 5-33.

Messick, S. (1996). Bridging cognition and personality in education: the role of style in performance and development. European Journal of Personality, 10, 353-376.

Newland, P., Powell, J., \& Creed, C. (1987). Understanding architectural designers' selective information handling. Design Studies, 8, 1-17.

Rutz, E. (2003). Learning styles and educational performance - Implications for professional development programs. CIEC Conference Proceedings, Tucson, AZ.

Schmitt, N. (1996). Uses and abuses of coefficient alpha. Psychological Assessment, 8, 350-353.

Schon, D. A. (1983). The reflective practitioner: How professionals think in action. New York: Basic Books.

Schon, D. A. (1984). The architectural studio as an exemplar of education for reflection-in action. Journal of Architectural Education, 38, 2-9.

Schon, D. A. (1987). Educating the reflective practitioner: Towards a new design for teaching in the professions. San Francisco: Jossey-Bass Publishers.

Slaats, A., Lodewijks, H. G. L. C., \& Van der Sanden, J. M. M. (1999). Learning styles in the secondary vocational education: disciplinary differences. Learning and Instruction, 9, 475-492.

Smith, D. M., \& Kolb, D. A. (1996). User's guide for the learning-style. Boston: McBer and Company.

Teymur, N. (1992). Architectural education: Issues in educational practice and policy. London: Question Press.

Teymur, N. (1996). Architectural history as 'educational object'. In A. Hardy, \& N. Teymur (Eds.), Architectural history and the studio (pp. 2666). London: Question Press.

Uluoğlu, B. (1990). Mimari Tasarım Eğitimi: Tasarım Bilgisi Bağlamında Stüdyo Eleştirileri. Unpublished Ph D. Thesis. İstanbul: İstanbul Technical University.

Uluoğlu, B. (2000). Design knowledge communicated in studio critiques. Design Studies, 21, 35-58.

Vermetten, Y. J., Lodewijks, H. G., \& Vermunt, J. D. (1999). Consistency and variability of learning strategies in different university courses. Higher Education, 37, 1-21.

Vince, R. (1998). Behind and beyond Kolb's learning cycle. Journal of Management Education, 22, 304-319.

Waks, L. J. (1999). Reflective practice in the design studio and teacher education. Journal of Curriculum Studies, 31, $303-316$.

Waks, L. J. (2001). Donald Schon's philosophy of design and design education. International Journal of Technology and Design Education, 11, $37-51$.

Willcoxson, L., \& Prosser, M. (1996). Kolb's learning style inventory (1985): review and further study of validity and reliability. British Journal of Educational Psychology, 66, 251-261. 